\title{
Castor Oil as Secondary Carbon Source for Production of Sophorolipids Using Starmerella bombicola NRRL Y-17069
}

\author{
Vinit Kamalkishor Bajaj and Uday S. Annapure* \\ Food Engineering and Technology Department, Institute of Chemical Technology (University under Section 3 of UGC Act 1956; Formerly \\ UDCT/ UICT), Nathalal Parikh Road, Matunga, Mumbai 400 019, INDIA.
}

\begin{abstract}
Sophorolipids (SLs), a prominent member of the biosurfactants family are produced in acidic and/or lactonic form by yeast Starmerella bombicola NRRL Y-17069 when grown on hydrophilic or hydrophobic or both carbon sources. In current study, ricinoleic acid rich castor oil $(10 \%)$ was used as hydrophobic and glycerol $(\mathbf{1 0 \%})$ was used as hydrophilic carbon source. The yields of $24.5 \pm 0.25 \mathrm{~g} / \mathrm{l}$ sophorolipids were analyzed by anthrone and HPLC method which further increased upto $40.24 \pm 0.76 \mathrm{~g} / \mathrm{l}$ sophorolipids using fed batch process at $5 \mathrm{~L}$ fermenter level. The structures of sophorolipids synthesized on castor oil were elucidated by liquid chromatography-mass spectrometer (LC-MS), ${ }^{13} \mathrm{C}$ and ${ }^{1} \mathrm{H}$ NMR. The results indicated that the ricinoleic acid (RA) gets hydroxylated at $\omega-1$ position but incorporated into sophorolipids through already available hydroxyl group at $12^{\text {th }}$ position. It resulted in the production of a novel sophorolipids with hydroxyl fatty acid as side chain and has applications as surfactant for novel drug delivery, anti microbial agent, cosmetic ingredient and emulsifier.
\end{abstract}

Key words: sophorolipids, ricinoleic acid,castor oil, Starmerella bombicola (NRRL Y-17069), direct incorporation, $\omega$-1 hydroxylation

\section{Introduction}

SURFace ACTive AgeNTS are one of the most regularly used materials that find various applications in day to day life activities. Currently marketed sources of surfactants are synthetic and petroleum based. Some natural surfactants like soap, lecithin or saponins have households and industrial application. Consumer awareness created a market for personal care and other home products, which are natural and environmental friendly. The need of biodegradable surfactants and surfactants derived from renewable resources has gained special attention across the globe $^{1)}$. The term biosurfactants refers to surfactant produced through fermentation processes. Biosurfactants have some advantages like biodegradability, selectivity, specific activity at excessive $\mathrm{pH}$, salinity and temperature over the chemical surfactants ${ }^{2}$. Sophorolipid, a glycolipid containing sophorose as dimeric sugar, is synthesized by a number of yeasts from Candida family ${ }^{3}$. Sophorolipid is an amphiphilic molecule having polar sophorose and non polar fatty acid part produced by pathway in Fig. 1. They are produced as a mixture of eight major components (lactone and acid forms) with varying degrees of acetylation at the 6 ' and 6 " positions of the sophorose moiety.

Sophorolipids (SLs) and its structural analogues are approved by USFDA(United State Food and Drug Administration) for good skin compatibility and excellent moisturizing properties. In addition to this, sophorolipids are potent bactericidal agents and are used in the treatment of acne, dandruff and body odours ${ }^{4)}$. Important actions like dermal fibroblast metabolism and collagen neosynthesis in protection of skin and hair are stimulated by sophorolipids. They also act as desquamating and depigmenting agents ${ }^{5,6)}$. Combinations of skin-cell stimulating property and antimicrobial activity made sophorolipids proficient for its use in therapeutic cosmetic applications.

Scientists have used glucose at 10\% w/v concentration and variety of vegetable oils ranging from soyabean oil ${ }^{7)}$, sunflower oill ${ }^{8)}$ and rapeseed oil ${ }^{9)}$. Using these oils it is impossible to compete the cost of sophorolipids with available chemical surfactant in market. Cheaper raw material such as animal fat, crude oleic acid, dairy waste water, molassess and whey waste were tried for SL production ${ }^{10)}$. In this

\footnotetext{
*Correspondence to: Uday S. Annapure, Food Engineering and Technology Department, Institute of Chemical Technology (University under Section 3 of UGC Act 1956; Formerly UDCT/ UICT), Nathalal Parikh Road, Matunga, Mumbai 400 019, INDIA.

E-mail: udayannapure@gmail.com

Accepted November 6, 2014 (received for review September 22, 2014)

Journal of Oleo Science ISSN 1345-8957 print / ISSN 1347-3352 online

http://www.jstage.jst.go.jp/browse/jos/ http://mc.manusriptcentral.com/jjocs
} 


\section{Candida bombicola NRRL Y-17069}

\section{Glycerol $+$}

Ricinoleic acid

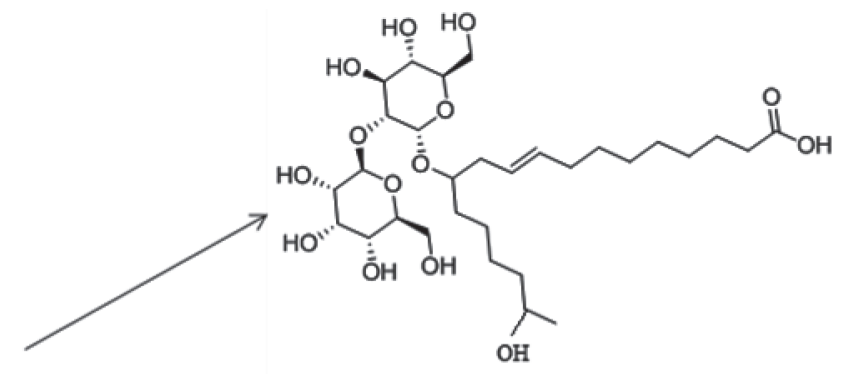

Acidic SLs

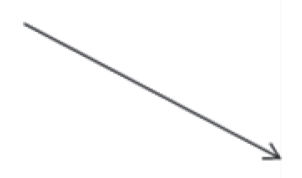

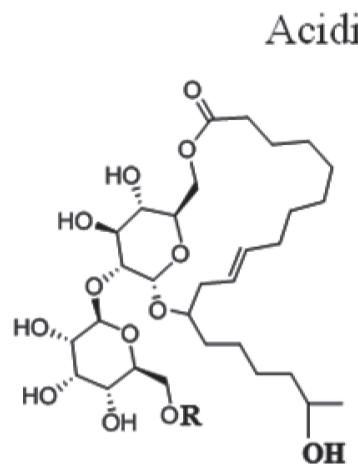

Lactonic SLs

Fig. 1 Synthesis pathway for production of sophorolipids from Starmerella bombicola NRRL Y-17069 using ricinoleic acid and glycerol.

study, non edible oil such as castor oil, present widely in India, along with glycerol is used as raw material for production of sophorolipids. Presence of ricinoleic acid, hydroxyl fatty acid, makes castor oil different and unique than any other vegetable oil for SLs production.

There are two pathways for sophorolipid biosynthesis first is hydroxylation of fatty acid generally $\mathrm{C}_{16}-\mathrm{C}_{18}$ by cytochrome $\mathrm{P} 450$ monooxygenase and second is direct incorporation of hydroxylated molecule such as alcohol, diol reported by ${ }^{11)}$. Castor oil form sophorolipids using both pathways as it contains ricinoleic acid which has hydroxyl functional group at $12^{\text {th }}$ position also have $\mathrm{C}_{18}$ carbon chain with free $\omega$ and $\omega-1$ position. This study proves for the first time that if a compound with $\mathrm{C}_{18}$ carbon chain with hydroxyl group and free $\omega$ or $\omega-1$ then it follows both the pathways hydroxylation as well as direct incorporation. Direct incorporation and hydroxylation at same time gives novel sophorolipid structure with hydroxyl fatty acid as side chain, which can be used as important material for especially as drug delivery carrier ${ }^{12,13)}$. These novel sophorolipid structures were elucidated with the help of liquid chromatography-mass spectrometer (LC-MS) and proton nuclear magnetic resonance and carbon nuclear magnetic resonance $\left({ }^{1} \mathrm{H},{ }^{13} \mathrm{C}-\mathrm{NMR}\right)$ spectroscopy.

\section{Material and Method:}

\subsection{Microbial culture and its Maintenance}

The yeast used in this study was Starmerella bombicola NRRL Y-17069. It was procured from Agricultural Research Service (ARS) Culture Collection, USDA, Peoria, USA. The strain was grown on medium containing: Yeast extract, (3 $\mathrm{g} / \mathrm{l})$; dextrose, (10 g/l); Urea (1 g/l)agar, (20 g/l) for $48 \mathrm{~h}$ at $27 \pm 2{ }^{\circ} \mathrm{C}$. Every four week organism was sub-cultured and maintained at $4{ }^{\circ} \mathrm{C}$ in refrigerator for further study.

\subsection{Materials}

Castor oil and oleic acid used for production of SLs was procured from Hi Media Pvt. Ltd. All chemicals such as glycerol (99\%), yeast extract, peptone, agar malt extract and anthrone were purchased from Hi Media Pvt. Ltd. and solvents (hexane, ethyl acetate, methanol, acetonitrile) were purchased from S. D. Fine Chemicals Ltd., India Respectively.

\subsection{Production of SLS}

Sodium chloride solution $(0.7 \%)$ was added to one week old slants to adjust the optical density as 1.5 at $660 \mathrm{~nm}$ and cell count as $2.87 \times 10^{8}$ cells / ml. About $5 \mathrm{ml}$ of this saline solution was added to basal medium $(50 \mathrm{ml})$ containing i.e., Glycerol (100 g/l); Yeast Extract (10 g/l); Urea (1 g/l) in 250 ml Erlenmeyer flask. After 48 h of incubation, castor oil (100 g/l) and in parallel experiment oleic acid (100 g/l)was added to flask and kept for 8 days on rotary shaker at $25 \pm$ 


\section{Sophorolipid Production Using Castor Oil}

$2^{\circ} \mathrm{C}$ and $200 \mathrm{rpm}$ without adjusting $\mathrm{pH}$ to produce SLs. Same procedure and media was used in a $5.0 \mathrm{l}$ stirred tank bioreactor, BIOSTAT Bplus (Sartorius, Germany), with a 2.0 $\mathrm{l}$ working volume. The fermentor was equipped with a $\mathrm{pH}$ probe (Type InPro 3030; Mettler Toledo) and a DO probe (Hamilton, Switzerland) and a fermentor vessel (UniVessels) having a height-to-diameter ratio of 2:1 with four baffles with six-flat-blade disc impellers (two) measuring 64 mm diameter, spaced $9.0 \mathrm{~cm}$ from each other for proper mixing. During the fermentation, the $\mathrm{pH}, \mathrm{DO}$, and aeration (gas flow)were monitored online, and sophorolipid and residual glycerol were analyzed offline.

\subsection{Isolation of SLs}

Procedure of isolation for oleic acid was explained in detail by Bajaj et al, our last published paper ${ }^{14)}$. In order to remove excess castor oil Hexane:chloroform (1:1) was used for (2-3 times), because castor oil is insoluble in hexane alone, differ to oleic acid removal. Remaining amount was weighed as amount of SLs. The residual oil was analyzed for fatty acid composition as per the A.O.C.S. Method Ce-1$62^{15)}$. The crude sophorolipids mixture was initially analyzed by anthrone method based on the quantitative release of glucose by acid hydrolysis of sophorose moiety of sophorolipids ${ }^{16)}$.

\subsection{Biomass and glycerol estimation}

The fermentation broth was extracted with ethyl acetate to remove residual oil and SLs after 192 hrs of fermentation. For determination of biomass, aqueous phase was centrifuged at $6,600 \mathrm{~g}$ at $25 \pm 2^{\circ} \mathrm{C}$ to separate cells from media. Supernatant after centrifugation was used to determine glycerol contain in remaining media using colorimetric method reported $\mathrm{in}^{17}$ ). Dry cell weight was determined after re-suspending the cells in small amount of water and drying till constant mass at $65^{\circ} \mathrm{C}$.

\subsection{Estimation, Identification and Characterization of SLs}

Estimation of SLs was done by extracting the fermented broth with ethyl acetate. This extract was dried under vacuum at $40^{\circ} \mathrm{C}$ to remove the solvent. The residue was further washed twice with hexane to remove the residual oil. The total yield of these partially purified SLs was measured by gravimetric measurement ${ }^{14)}$, anthrone and HPLC method.

\subsubsection{Thin Layer Chromatography (TLC)}

The formation of different components was examined by TLC, on silica gel(Make: Merck, Darmstadt, Germany; silica layer thickness $2 \mathrm{~mm}$ ) as a stationary phase. Movement of sophorolipids took place from solvent base line towards the solvent front, using chloroform/methanol/water (65:15:2, v/ $\mathrm{v} / \mathrm{v})$ as mobile phase. The displacements of sophorolipids were visualized by spraying or dipping the TLC plate in methanol $/ \mathrm{H}_{2} \mathrm{SO}_{4}(50: 50, \mathrm{v} / \mathrm{v})$ reagent and heating at $100^{\circ} \mathrm{C}$ for $20 \mathrm{~min}$ in oven.

2.6.2 High Performance Liquid Chromatography (HPLC)

Crude sophorolipids produced on castor oil and oleic acids were separated and quantified by HPLC (model HITACHI L-2350) using UV variable wavelength detector at 207 nm. Column- Zorbax SB C18, $2 \times 100$ mm, 1.8 um, Mobile phase (A) $\mathrm{H}_{2} \mathrm{O}+0.1 \%$ Formic Acid, (B) $90 \%$ ACN + $10 \% \mathrm{H}_{2} \mathrm{O}+0.1 \%$ Formic Acid. Initially A - $90 \%$ and B $10 \%$ were passed through column for $5 \mathrm{~min}$ and then the mobile phase composition was changed to A - $10 \%$ and B $90 \%$ in $60 \mathrm{~min}$ and maintained for $5 \mathrm{~min}$.

2.6.3 Fourier Transform Infrared (FTIR) and ${ }^{1} \mathrm{H}$ and ${ }^{13} \mathrm{C}$ Nuclear Magnetic Resonance Spectroscopy $\left({ }^{1} \mathrm{H}\right.$ and ${ }^{13} \mathrm{C} \mathrm{NMR}$ )

The structural recognition and characterization of sophorolipids was done by Fourier-transform infrared spectroscopy (FTIR) with a Perkin-Elmer Spectrum-One spectrophotometer, USA operated in the diffuse reflectance mode at resolution of $4 \mathrm{~cm}$. Further the structure of sophorolipids were confirmed by ${ }^{1} \mathrm{H}$ and ${ }^{13} \mathrm{C}$ NMR obtained with Varian Inova 500 NMR Spectrometer (model $500 \mathrm{MHz}$, Varian, USA) recorded in chemical shifts with respect to tetramethylsilane (TMS) as an internal reference standard in $\mathrm{CDCl}_{3}$ as solvent. ${ }^{1} \mathrm{H}$ and ${ }^{13} \mathrm{C} \mathrm{NMR}$ analysis was completed at National Facility for High-Field NMR, TIFR, Mumbai, India.

2.6.4 Liquid Chromatography-Mass Spectrometer (LCMS)

Structures of sophorolipids were also identified by positive ESI tandem mass spectra (MS Q-TOF LC-MS Agilent 6550 A) provided by Sophisticated Analytical Instrument Facility (SAIF), IIT Bombay, Mumbai, India.

2.6.5 Gas Chromatography (GC)

The presence of ricinoleic fatty acids in sophorolipids was confirmed by GC analysis and results were compared with methyl ester of castor oil by GC. The samples were hydrolysed and esterified by adding $0.4 \mathrm{ml}$ of $20 \mathrm{mM}$ cupric acetate monohydrate in methanol and $2 \mathrm{ml}$ of $0.5 \mathrm{~N} \mathrm{HCl}$ in Hydranal. The reaction mixture was allowed to stand for the specified time $(2-3 \mathrm{~h})$ at $37 \pm 2^{\circ} \mathrm{C}$ to convert fatty acids into fatty acid methyl esters (FAME). The reaction was stopped with the addition of 3-4 ml of water. Extraction of FAME mixture was done thrice using $2 \mathrm{ml}$ hexane and hexane layer was used for gas chromatography (GC) analy$\operatorname{sis}^{18)}$. All compounds were identified by comparison of their retention times with those of known standards using Agilent GC equipped with DB-23 capillary column (60 m $\times$ $0.25 \mathrm{~mm}$ ID $\times 0.25 \mu \mathrm{FT}$, Agilent). The injector and FID detector were maintained at $260^{\circ} \mathrm{C}$ and the column oven was programmed to increase from 140 to $240^{\circ} \mathrm{C}$ at $4^{\circ} \mathrm{C} / \mathrm{min}$. Split ratio was adjusted to $5: 1$. Helium at the flow of $1 \mathrm{ml} /$ min was used as the carrier gas. FAMEs were quantified by GC and compared with standards from Nu- Check - Prep, Inc., MN, USA. 


\section{Results}

The current work focuses on the novel chemical structure and characterization of sophorolipids synthesized on glycerol and castor oil as a primary and secondary carbon source respectively. Various tests were conducted to analyse castor oil and oleic acid shown in Table 1. The castor oil contains ricinoleic acid and thus it is different from other vegetable oils.

\subsection{Effect of castor oil on sophorolipids structure}

First step in utilization of fatty acid for sophorolipids synthesis is hydroxylation of ultimate or penultimate carbon atom of fatty acid by cytochrome P 450 monooxygenase (P450). Sophorolipids have been previously synthesized using various raw materials like canola oil, oleic acid, sunflower oil, $\alpha$-linoleic acid, soybean oil. The use of water soluble substrate like glucose $10 \%$ or glycerol $10 \%$ produce sophorolipid by de novo synthesis but when water soluble substrates used with hydrophobic substrate (10\%) gives higher yield. In the current study, castor oil (10\%) was used as hydrophobic carbon source along with glycerol (10\%) for production of sophorolipids using Starmerella bombicola NRRL Y-17069. Figure 2 explains importance of fed batch culture to improve sophorolipid production. Production profile of sophorolipid using castor oil is shown in Fig. 2 which clearly depicts rate of sophorolipid synthesis was high during first 120 hrs of fermentation and after which rate of synthesis has decreased due to accumulation of unused ricinoleic acid which inhibit microbial growth. Changes in sophorolipids production using castor oil were compared with that of oleic acid in Table 2.

\subsection{Fatty acid composition of residual oil}

Castor oil composed of fatty acid like ricinoleic acid $(74.4 \%)$, palmitic acid $(3.2 \%)$, oleic acid $(8.9 \%)$, linoleic

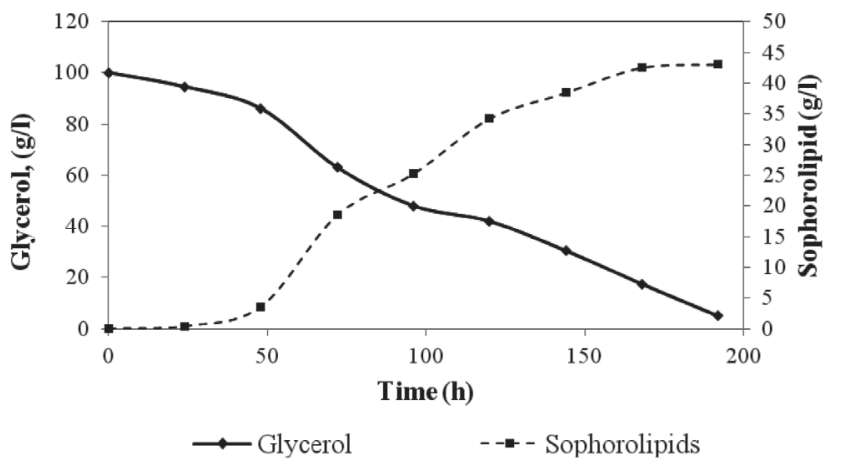

Fig. 2 Production profile of sophorolipids using castor oil and glycerol as substrate. Castor oil is added in same quantity $(10 \mathrm{~g} / \mathrm{l})$ every $24 \mathrm{hr}$ except last $24 \mathrm{hr}(30 \mathrm{~g} / \mathrm{l})$ is added.

$\operatorname{acid}(8.2)$ and stearic $\operatorname{acid}(4.1 \%)$. After fermentation it was observed that residual castor oil contain ricinoleic acid, palmitic acid, stearic acid, oleic acid, linoleic acid as shown in Table 3. This results indicated that ricinoleic acid has higher percentage utilization (76\%) compared with other fatty acid like palmitic acid, oleic acid, linoleic acid and stearic acid. This may be due to availability of $-\mathrm{OH}$ group at $12^{\text {th }}$ position.

\subsection{Characterization of sophorolipids by 1 NMR, FTIR, LCMS and GC}

Thin Layer Chromatography (TLC) of sophorolipids produced using castor oil showed spots with similar Rf values corresponding to that produced using oleic acid as raw material(Data not shown). An FTIR spectrum of crude sophorolipids (Fig. 3) produced using castor oil reveals broad band at $3419 \mathrm{~cm}^{-1}$ corresponds to O-H stretch while band at $2925 \mathrm{~cm}^{-1}$ and $2853 \mathrm{~cm}^{-1}$ observed due to asym-

Table 1 Composition for oils used for sophorolipids production.

\begin{tabular}{|c|c|c|c|c|}
\hline $\begin{array}{l}\text { Hydrophobic } \\
\text { Substrate }\end{array}$ & $\begin{array}{c}\text { Fatty Acid } \\
\text { Composition }(\% \mathrm{~W} / \\
\mathrm{W})^{€} \text { by A.O.C.S. } \\
\text { method Ce-1-62 }\end{array}$ & $\begin{array}{l}\text { Acid Value (mgKOH/ } \\
\text { g) A.O.C.S. Te-La-64 }\end{array}$ & $\begin{array}{l}\text { Iodine Value (\%) } \\
\text { A.O.C.S. Tg-la-64 }\end{array}$ & $\begin{array}{c}\text { Saponification Value } \\
\text { (mgKOH/g) A.O.C.S. } \\
\text { Tl-la-64 }\end{array}$ \\
\hline Oleic Acid & $\begin{array}{l}C_{16: 0}-18.23 \pm 0.15 \\
C_{18: 0}-5.00 \pm 0.23 \\
C_{18: 1}-70.12 \pm 0.12 \\
C_{18: 2}-5.32 \pm 0.20\end{array}$ & 197.5 & 88.9 & 200.1 \\
\hline Castor Oil & $\begin{array}{l}C_{16: 0}-3.1 \pm 0.14 \\
C_{18: 0}-4.8 \pm 0.27 \\
C_{18: 1}-8.9 \pm 0.11 \\
C_{18: 2}-8.8 \pm 0.21 \\
R A-74.23 \pm 0.25\end{array}$ & 0.45 & 84.1 & 180.5 \\
\hline
\end{tabular}

\footnotetext{
${ }^{\epsilon}$ All the experiments are done in triplicate and the results are mean of three experiments \pm standard deviation
} 
Table 2 Comparison of sophorolipids production using castor oil and oleic acid at $196 \mathrm{hrs}$.

\begin{tabular}{lcccc}
\hline & $\begin{array}{c}\text { Yield of } \\
\text { sophorolipids* }\end{array}$ & $\begin{array}{c}\text { Residual glycerine } \\
(\% \mathrm{w} / \mathrm{w})\end{array}$ & $\begin{array}{c}\text { Residual oil } \\
(\% \mathrm{w} / \mathrm{v})\end{array}$ & $\begin{array}{c}\text { Biomass } \\
(\mathrm{g} / \mathrm{l}) *\end{array}$ \\
\hline Oleic acid + glycerol & $52.34 \pm 0.64$ & $3.45 \pm 1.01$ & 1.11 & $11.24 \pm 2.1$ \\
Castor oil + glycerol & $24.42 \pm 1.14$ & $6.75 \pm 0.32$ & 7.84 & $7.85 \pm 0.29$ \\
Oleic acid + glycerol (Fed batch) & $62.58 \pm 0.95$ & $1.98 \pm 0.58$ & 0.86 & $11.35 \pm 0.57$ \\
Castor oil + glycerol (Fed batch) & $40.23 \pm 1.23$ & $2.24 \pm 0.21$ & 5.78 & $11.06 \pm 0.3$ \\
\hline
\end{tabular}

*All the experiments are done in triplicate and the results are mean of three experiments \pm standard deviation

Table 3 Residual fatty acid composition of oleic acid and castor oil at $196 \mathrm{hrs}$.

\begin{tabular}{ccccc}
\hline \multirow{2}{*}{ Fatty acids } & \multicolumn{2}{c}{ Oleic acid + glycerol } & \multicolumn{2}{c}{ Castor oil + glycerol } \\
\cline { 2 - 5 } & Composition $^{\phi}$ & \% Utilization & Composition $^{\phi}$ & \% Utilization \\
\hline C16 & $15.23 \pm 1.23$ & 2.32 & $4.51 \pm 0.98$ & 3.12 \\
C18:0 & $5.12 \pm 1.52$ & 3.56 & $9.69 \pm 1.37$ & 8.81 \\
C18:1 & $65.23 \pm 1.92$ & 90.05 & $9.20 \pm 2.04$ & 10.64 \\
C18:2 & $10.65 \pm 1.47$ & 4.21 & $5.24 \pm 1.15$ & 2.14 \\
Ricinoleic acid & ND & ND & $69.59 \pm 2.21$ & 76.29 \\
\hline
\end{tabular}

${ }^{\phi}$ All the experiments are done in triplicate and the results are mean of three experiments \pm standard deviation

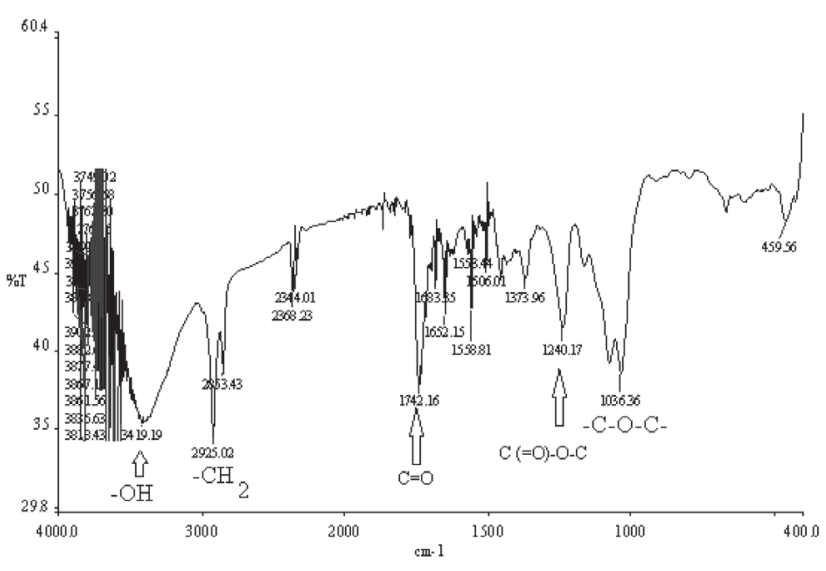

Fig. 3 FTIR of crude sophorolipids indicating all functional group. Crude sophorolipids were mixed with $\mathrm{KBr}$ and pallet was formed for FTIR analysis.

metrical stretching $\left(\mathrm{v}_{\text {as }} \mathrm{CH}_{2}\right)$ and symmetrical stretching $\left(\mathrm{v}_{\mathrm{s}} \mathrm{CH}_{2}\right)$ of methylene respectively. Enclosure of band at $1742 \mathrm{~cm}^{-1}$ was due to $\mathrm{C}=\mathrm{O}$ stretching of lactones, esters or acids. C-O stretch of $\mathrm{C}(=\mathrm{O})-\mathrm{O}-\mathrm{C}$ at $1240 \mathrm{~cm}^{-1}$ which confirms sophorolipids as lactone appears ${ }^{19)}$. Bands at 1036 $\mathrm{cm}^{-1}$ and $1080 \mathrm{~cm}^{-1}$ refer to ether linkages. Further the structures were characterised by ${ }^{1} \mathrm{H}$ NMR and ${ }^{13} \mathrm{C}$ NMR. Figure 4 gives the emphasis on $\mathrm{C}^{13} \mathrm{NMR}$, signal at 130.02 ppm and 125.79 ppm which confirm presence of two $-\mathrm{CH}=$ CH- group in produced SLs. Also signals at $170 \mathrm{ppm}$ to 173 ppm validate presence of ester or lactonic group ${ }^{20)}$. Several
$-\mathrm{CH}_{2}$ - from fatty acid chain were resonated in between $20.72 \mathrm{ppm}$ to $38.42 \mathrm{ppm}$. The spectrum also revealed signals of glucose-C-1 at $103.94 \mathrm{ppm}$, glucose-C-1' at 102.16 ppm $(-\mathrm{O}-\mathrm{CH}-\mathrm{O}-)^{21)}$, fatty acid $\left(-\mathrm{HC}=\mathrm{CH}-\mathrm{CH}_{2}-\mathrm{CH}-\right.$ $\mathrm{O}$ - sophorose) at $87.34 \mathrm{ppm}^{22)}$ (Sophorolipid produced using oleic acid doesn't have this peak), glucose-C- 6 at $63.66 \mathrm{ppm}$ and glucose-C-6 ' at $62.12 \mathrm{ppm}^{23)}$. In sophorolipids produced using oleic acid the peak of carbon attached to sophorose moiety was observed at 76.34 i.e. $\omega-1$ carbon ${ }^{24)}$. In case of ricinoleic acid, ${ }^{13} \mathrm{C}$ NMR peak of $12^{\text {th }}$ carbon was detected at $73.1 \mathrm{ppm}^{25)}$ which is shifted to $87.34 \mathrm{ppm}$. This shifting of peak at 87.34 confirms attachment of sophorose to $12^{\text {th }}$ carbon of ricinoleic acid.

$\mathrm{H}^{1} \mathrm{NMR}$ (Table 4) of sophorolipids illustrates main functional groups from sophorolipids like $-\mathrm{COCH}_{3}$ of acetyl moiety, $\mathrm{CH}-\mathrm{OH}$ of $\omega-1$ position and $-\mathrm{CH}=\mathrm{CH}$ - give signals at $2.05,4.03,5.35$ respectively. Fatty acid chain moiety in sophorolipids structure shows peaks from $1.2-1.4 \mathrm{ppm}^{20)}$. It was observed in the LCMS of sophorolipids that peak at $39.7 \mathrm{~min}$ and $44.14 \mathrm{~min}$ depict acidic and lactonic sophorolipids respectively with $\omega-1-\mathrm{OH}$ group (Fig. 5 and 6).

\section{Discussion}

Castor oil contains ricinoleic acid which has the bactericidal and fungicidal property because of presence of $-\mathrm{OH}$ group at $12^{\text {th }}$ position. As a result, when castor oil (10\%) is added to fermentor it resulted in lower yield compare to oleic acid i.e. $24.45 \pm 0.25 \mathrm{~g} / \mathrm{l}$ compare to $52.34 \pm 076 \mathrm{~g} / \mathrm{l}^{26)}$. 


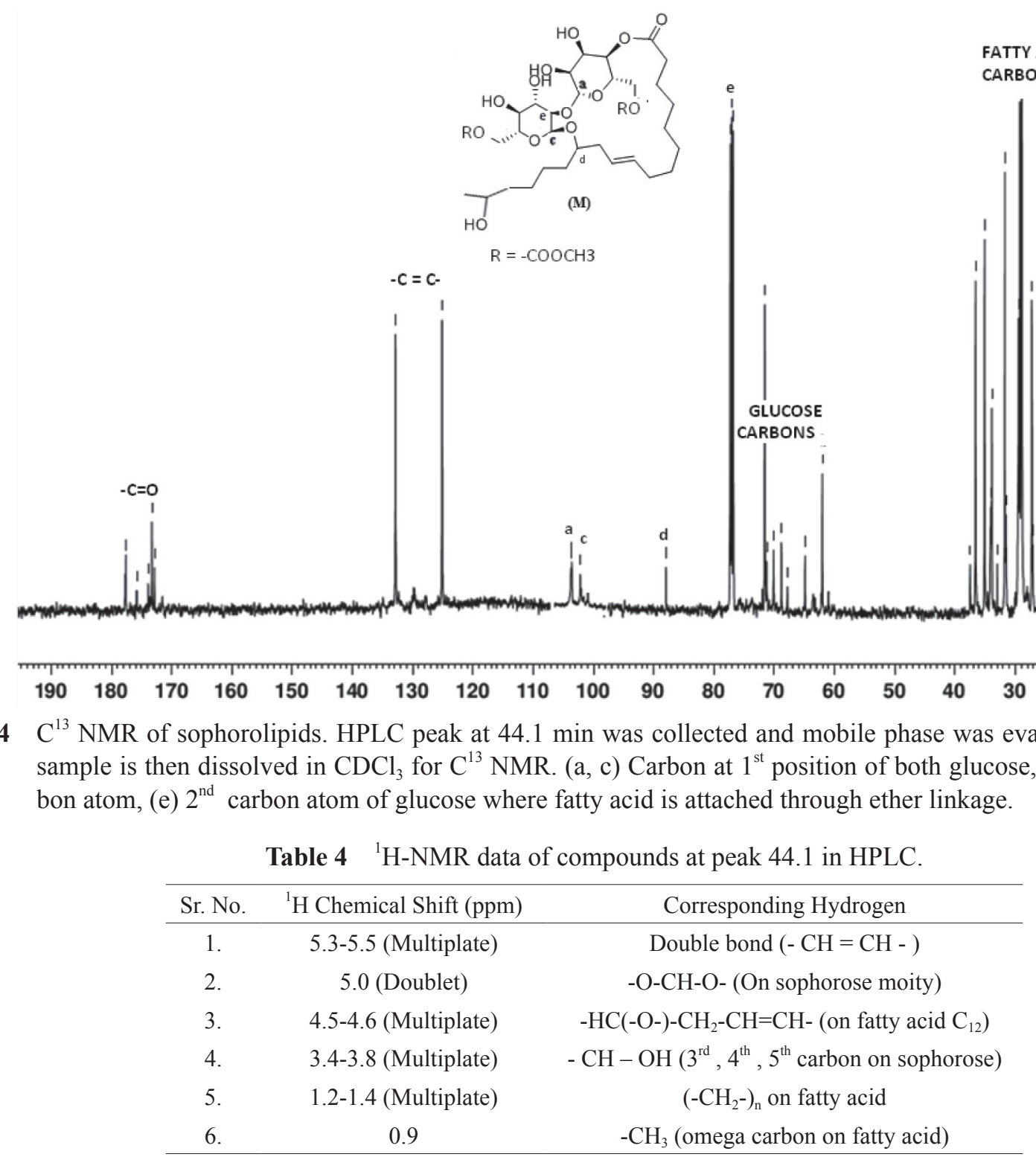

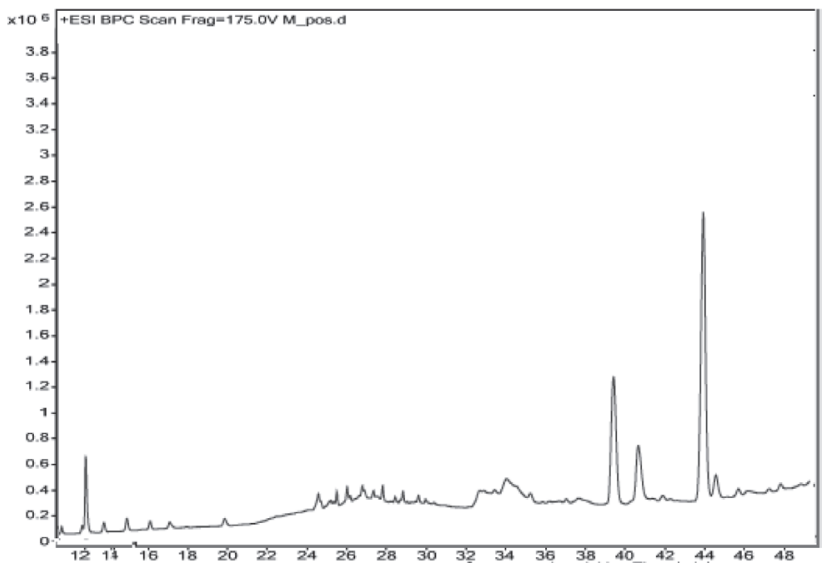

Fig. 5 HPLC of sophorolipids showing peaks at 39.7 and 44.1 as major peaks.
In current study above problem was solved using fed batch technique where organism comes in contact with concentration below inhibitory effect of ricinoleic acid at given time interval and hence sophorolipid production increases from $24.45 \pm 0.25 \mathrm{~g} / \mathrm{l}$ to $40.23 \pm 1.34 \mathrm{~g} / \mathrm{l}$. Moreover castor oil may give partly new sophorolipids than typical sophorolipids produced using oleic acid with increased antimicrobial activity by two pathways explained earlier in introduction of this research paper.

Sophorolipids production is dependent on the structure of hydrophobic carbon source used during fermentation i.e., fatty acid moiety which also reflects in the product sophorolipids. Fatty acids having $\mathrm{C}_{16}$ or $\mathrm{C}_{18}$ carbon chain are hydroxylated at $\omega$ or $\omega-1$ position by cytochrome P450 monooxygenase (P450) and then glycolipid is formed by etherifying fatty acid with sophorose moiety at $4^{\text {th }}$ position 

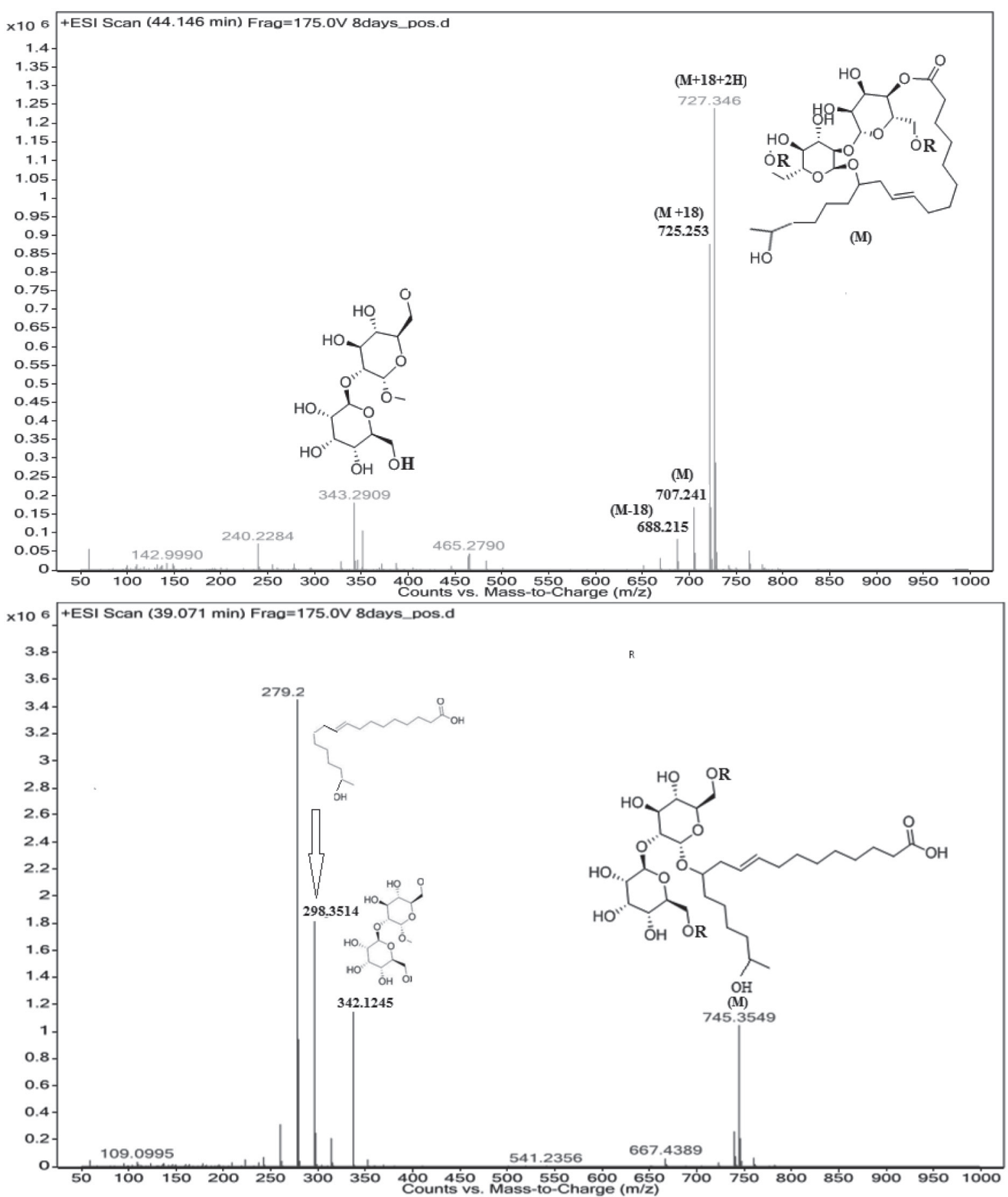

Fig. 6 Mass fragmentation of acidic and lactonic sophorolipids. HPLC peak from 44.1 and 39.07 were collected and LCMS was done in system having QTOF mass spectrophotometer.

of either glucose molecule. The fatty acids are incorporated via $\omega$ or $\omega-1$ hydroxylation into sophorolipids only if they have $\mathrm{C}_{16}$ or $\mathrm{C}_{18}$ carbon chain. Certain reports are available were the substrate is $\mathrm{C}_{12}$ but already hydroxylated and does not have free $\omega$ or $\omega-1$ for example alcohols, diols ${ }^{27)}$. In case of castor oil both the pathways are possible as the chain length is $\mathrm{C}_{18}$ with free $\omega$ or $\omega-1$ position and it also have -OH group for direct incorporation. This study proves that compound with $\mathrm{C}_{18}$ having hydroxyl group and free $\omega$ or $\omega-1$ it follows both the pathways of hydroxylation as well as direct incorporation.

It was observed from the above all analysis results that 
presence of glycoside linkage is at $12^{\text {th }}$ position of ricinoleic acid. But as the ricinoleic acid having $\mathrm{C}_{18}$ carbon chain it gets hydrolysed at $\omega-1$ position and sophorose attachment takes place at either of the two positions. Peak was found at $725\left(\mathrm{M}+\mathrm{H}_{2} \mathrm{O}\right)$ corresponds to diacetylated lactonic sophorolipid with molecular weight 707 (ricinoleic acid side chain) and peak at $\mathrm{m} / \mathrm{z}$ ratio of 745 corresponds to diacetylated acidic SLs. The anion at m/z ratio 342 and 298 indicated presence of sophorose and ricinoleic acid which confirms presence of $-\mathrm{OH}$ group on side chain i.e. hydroxylation occurred at $\omega-1$ position (Fig. 5 ). Figure 5 also explains about the different fragmentation pattern of acidic and lactonic sophorolipid. Glycoside bond form either at $\omega-6$ or at $\omega-1,{ }^{13} \mathrm{C}$ NMR results proves that glycosidic bond was formed at $12^{\text {th }}$ i.e. $\omega-6$ position (Fig. 4 ).

Bhangale $e t a l .{ }^{28)}$ has worked on sophorolipid production using castor oil but with growth inhibition and lower yield problems which were solved using fed batch technique in fermentor $(5 \mathrm{~L})$ with optimized aeration and agitation. Bhangale et al. also explained hydroxylation at $\omega-1$ position is not required for sophorolipids production in presence of castor oil with reference of Brakemeier et $a l .{ }^{29)}$. Substrates used in Brakemeier et al. study are 1-dodecanol and 2, 3, 4-dodecanone which are not substrate for cytochrome P450 enzyme and cannot be correlated with castor oil. 1-dodecanol and 2,3,4-dodecanone substrate does not have length in between 22.55-25.05 $\mathrm{A}^{\circ}$ which is required for hydroxylation, at $\omega$ or $\omega-1$ position, by cytochrome P450 enzyme. However in the present study, it is proved that irrespective of the hydroxylation requirement Starmerrela bombicola NRRL Y-17069 hydroxylates ricinoleic acid at $\omega-1$ due to its length $\left(\mathrm{C}_{18}\right)$ in between 22.55$25.05 \mathrm{~A}^{\circ}$. This supports the results of Tulloch et $a l^{30)}$, irrespective of the shape, length of the fatty molecule matters for hydroxylation because P450 enzyme converts fatty acid of length 22.55-25.05 $\mathrm{A}^{\circ}$ very easily irrespective of the groups attached to it.

In all the previous sophorolipid studies ${ }^{14,28)}$, hexane was used as solvent to remove unused residual oil. This study reveals that castor oil and sophorolipids both are insoluble in hexane. In order to remove unused castor oil from sophorolipid mixture chloroform: hexane mixture (1:1), in which castor oil is soluble, but sophorolipid is not was used.

\section{Conclusions}

The sophorolipids are well known biosurfactant having antimicrobial activity which varies on the basis of the structure of the compounds. The castor oil along with the glycerol gives production of partly new sophorolipids with hydroxylation and direct incorporation both. Addition of castor oil at particular interval in the media confers pro- duction of sophorolipids with maximum conversion. The growth of cells was maximised with fed batch culture technique compare to batch production. The novel sophorolipids produced on ricinoleic acid rich castor oil reserved its ricinoleic acid moiety hence; it may show the combined effect of castor oil and sophorolipid. Sophorose group attached either at $\omega-6$ position or at $\omega-1$ position and other $\mathrm{OH}$ group remain free, contradictory to sophorolipids produced using oleic acid which does not have free - $\mathrm{OH}$ group in side chain. These results improve the effect of sophorolipids as antimicrobial and emulsifier and can be used as a tool for developing new and more effective application of sophorolipids.

\section{Acknowledgement}

Authors are thankful to the Union Grant Commission special assistance program (UGC-SAP), India, for providing financial assistance during the course of this research. We also would like to thank Dr. Ajay Dalai for his kind support.

\section{References}

1) Kitamoto, D.; Isoda, H.; Nakahara, T. Functions and potential applications of glycolipid biosurfactants from energy-saving materials to gene delivery carriers. $J$. Biosci. Bioengin. 94, 187-201 (2002).

2) Banat, I. M.; Makkar, R. S.; Cameotra, S. S. Potential commercial applications of microbial surfactants. Appl. Microbiol. Biotechnol. 53, 495-508(2000).

3) Kurtzman, C. P.; Price, N. P. J.; Ray, K. J.; Kuo, T. M. Production of sophorolipid biosurfactants by multiple species of the Starmerella (Candida) bombicola yeast clade. FEMS Microbiol. Let. 311, 140-146 (2010).

4) Magar, H.; Rothlisberger, R.; Wagner, F. European Patent, 0209783 (1987).

5) Maingault. US Patent 5981497 (1999).

6) Hillion, G.; Marchal, R.; Stoltz, C.; Borzeix, F. US Patent 5756471A (1998).

7) Daverey, A.; Pakshirajan, K. Production, characterization, and properties of sophorolipids from the yeast Candida bombicola using a low-cost fermentative medium. Appl. Biochem. Biotechnol. 158, 663-674 (2009).

8) Casas, J. A.; García-Ochoa, F. Sophorolipid production by Candida bombicola: medium composition and culture methods. J. Biosci. Bioeng. 88, 488-494(1999).

9) Daniel, H. J.; Matthias, R.; Christoph, S. Production of sophorolipids in high concentration from deproteinized whey and rapeseed oil in a two stage fed batch process using Candida bombicola ATCC 22214 and 
Cryptococcus curvatus ATCC 20509. Biotechnol. Lett. 20, 1153-1156 (1998).

10) Deshpane, M.; Daniels, L. Evaluation of sophorolipid biosurfactant production by Candida bombicola using animal fat. Bioresourse Technol. 54, 143-150 (1995).

11) Bogaert, I. V.; Fleurackers, S.; Kerrebroeck, S. V.; Develter, D.; Soetaert, W. Production of new to nature sophorolipids by cultivating yeast Candida bombicola on unconventional hydrophobic substrates. Biotechnol. Bioeng. 108, 734-741 (2011).

12) Bajaj V. K. Ind. Pat. Application Number 2696/ MUM/2013 (2013).

13) Bajaj V. K. Ind. Pat. application number 3774/ MUM/2013 (2013).

14) Bajaj, V. K.; Tiley, A.; Annapure, U. S. Enhanced production of bioactive sophorolipids by Candida bombicola NRRL Y-17069 by design of experiment approach with successive purification and characterization. J. Oleo Sci. 61, 377-386 (2012).

15) Firestone D. Official Methods and Recommended Practices of the American Oil Chemists' Society, AOCS Press, Champaign (1994).

16) Hodge, J. E.; Hofreiter B. T. Methods in Carbohydrate Chemistry. In: Wilster, R. L., Wolfrom, M. L., Vol 1 Academic Press Inc, New York, pp 380-394 (1962).

17) Lynch, H. C.; Yang, Y. Degradation products of clavulanic acid promote clavulanic acid production in cultures of Streptomyces clavuligerus. Enzyme. Microb. Tech. 34, 48-54(2004).

18) Hoshi, M.; Williams, M.; Kishimoto, Y. Esterification of fatty acids at room temperature by chloroform-methanolic HCl-cupric acetate. J. Lipid Res. 4, 599-601 (1973).

19) Chatwal, G.; Anand S. Instrumental methods of chemical analysis. In: Infra-red spectrophotometry. Eds $5^{\text {th }}$. Himalaya publishing house, Delhi(India), pp 23-48 (2002).

20) Chatwal G.; Anand S. Instrumental methods of chemical analysis. In: Nuclear Magnetic Resonance. Eds $5^{\text {th }}$.
Himalaya publishing house, Delhi(India), pp 92-118 (2002).

21) Mao, J. D.; Schmidt, R. K. Separation of aromatic-carbon ${ }^{13} \mathrm{C}$ NMR signals from di-oxygenated alkyl bands by a chemical-shift-anisotropy filter. Solid State Nucl. Mag. 26, 36-45 (2004).

22) Zhang, L.; Zha, Z.; Zhang, Z.; Li, Y.; Wang, Z. An electrochemical tandem reaction: one-pot synthesis of homoallylic alcohols from alcohols in aqueous media. Chem. Commun. (Camb) . 46, 7196-7198(2010).

23) Daverey, A.; Pakshirajan, K.; Sangeetha, P. Sophorolipids Production by Candida bombicola using synthetic Dairy Wastewater. Int. J. Environ. Sci. Eng. 1, 173175 (2009).

24) Bisht, K. S.; Gross, R. A.; Kaplan, D. L. Enzyme-Mediated Regioselective Acylations of Sophorolipids. $J$. Org. Chem. 64, 780-789 (1999).

25) Hayes, D. G.; Mannam, V. K.; Ye, R.; Zhao, H.; Ortega, S.; Claudia Montiel, M. Modification of oligo-ricinoleic acid and its derivatives with 10 -undecenoic acid via lipase-catalyzed esterification. Polymers 4, 1037-1055 (2012).

26) Shin, S. Y.; Kim, H. R.; Kang, S. C. Antibacterial Activity of various hydroxy fatty acids bioconveted by Pseudomonas aeruginosa PR3. Agric. Chem. Biotechnol. 47, 205-208 (2004).

27) Bogaert, I. V.; Develter, D.; Fleurackers, S. US Patent US 2011/0136110 A1, (2009).

28) Bhangale, A.; Wadekar, S.; Kale, S. B.; Bhowmick, D.; Pratap, A. Production of sophorolipids synthesized on castor oil with glucose and glycerol by using Starmerella bombicola (ATCC 22214). Eur. J. Lipid Sci. Technol. 116, 336-343(2014).

29) Brakemeier, A.; Wullbrandt, D.; Lang, S. Microbial alkyl-sophorosides based on 1dodecanol or 2-, 3-or 4dodecanones. Biotechnol. Lett. 20, 215-218(1998).

30) Tulloch, A.; Spencer, J.; Gorin, P. A. J. Fermentation of long chain compounds by Torulopsis magnolia. Can. J. Chem. 40, 1326-1338(1962). 